\title{
Review Article \\ The Role of Peroxisome Proliferator-Activated Receptors in Pulmonary Vascular Disease
}

\author{
Rachel E. Nisbet, Roy L. Sutliff, and C. Michael Hart \\ Department of Medicine, Emory University, Atlanta Veterans Affairs Medical Center, Decatur, GA 30033, USA
}

Received 1 January 2007; Accepted 30 April 2007

Recommended by Jesse Roman

\begin{abstract}
Peroxisome proliferator-activated receptors (PPARs) are ligand-activated transcription factors belonging to the nuclear hormone receptor superfamily that regulate diverse physiological processes ranging from lipogenesis to inflammation. Recent evidence has established potential roles of PPARs in both systemic and pulmonary vascular disease and function. Existing treatment strategies for pulmonary hypertension, the most common manifestation of pulmonary vascular disease, are limited by an incomplete understanding of the underlying disease pathogenesis and lack of efficacy indicating an urgent need for new approaches to treat this disorder. Derangements in pulmonary endothelial-derived mediators and endothelial dysfunction have been shown to play a pivotal role in pulmonary hypertension pathogenesis. Therefore, the following review will focus on selected mediators implicated in pulmonary vascular dysfunction and evidence that PPARs, in particular PPAR $\gamma$, participate in their regulation and may provide a potential novel therapeutic target for the treatment of pulmonary hypertension.
\end{abstract}

Copyright (c) 2007 Rachel E. Nisbet et al. This is an open access article distributed under the Creative Commons Attribution License, which permits unrestricted use, distribution, and reproduction in any medium, provided the original work is properly cited.

\section{INTRODUCTION}

Originally described in 1990, peroxisome proliferatoractivated receptors (PPARs) are ligand-activated transcription factors belonging to the nuclear hormone receptor superfamily [1]. PPARs have been implicated in diverse disorders including cancer, diabetes, and atherosclerosis, and activation of these receptors regulates diverse physiological processes ranging from lipogenesis to inflammation. Three distinct PPAR subclasses have been identified; PPAR $\alpha$, $\operatorname{PPAR} \beta / \delta$, and PPAR $\gamma$. These isotypes are encoded by separate genes and exhibit different tissue distributions and function. PPAR $\alpha$ is predominantly expressed in liver, heart, kidney, and muscle where it regulates genes involved in lipid metabolism. PPAR $\beta / \delta$ is a more ubiquitously expressed isoform that stimulates fatty acid oxidation in heart and skeletal muscle [2] and whose diverse functions include cell differentiation [3] and participation in placental development, cancer [4], wound repair [5], and atherosclerosis [6]. PPAR $\gamma$, expressed in many tissues including adipose, vascular endothelium and smooth muscle, and heart among others, is an important regulator of genes involved in cellular differentiation, particularly adipogenesis, lipid metabolism, and glucose homeostasis. More recently, PPAR $y$ has been shown to play a pivotal role in cell growth, inflammation, apoptosis, and angiogenesis [7-10]. There is limited evidence for the potential roles of PPAR $\alpha$ and $\operatorname{PPAR} \beta / \delta$ in pulmonary vascular function and disease. However, recent studies have established that pulmonary hypertension in humans is associated with reduced PPAR $\gamma$ expression and that PPAR $\gamma$ ligands can attenuate the development of pulmonary hypertension in several experimental models. This review will summarize recent work implicating PPAR $\gamma$ in pulmonary vascular disease.

\section{PPAR BIOLOGY}

Ligand binding stimulates the PPAR to form a heterodimer with the retinoid X receptor (RXR) in the cytoplasm [11]. Once activated, the PPAR/RXR heterodimer translocates to the nucleus where the complex binds to PPAR response elements (PPRE) in the promoter region of responsive genes to modulate transcriptional activity. Gene regulation involves ligand-induced conformational changes in the PPAR receptor that mediate interaction with specific coactivator (e.g. steroid receptor coactivator-1 and p300) and corepressor molecules. The coactivator proteins either possess histone acetyltransferase activity or recruit other proteins with this 
activity to the transcription start site. Acetylation of histone proteins alters chromatin structure, facilitating the binding of RNA polymerase and the initiation of transcription [12]. PPARs can also repress gene expression by interfering with other signaling pathways and by recruiting corepressors to unliganded PPARs [13].

Structurally diverse ligands activate PPARs. For example, ligands of PPAR $\alpha$ include polyunsaturated fatty acids, arachidonic acid metabolites such as leukotriene $\mathrm{B}_{4}$, and synthetic fibrate compounds used in the treatment of dyslipidemia. Ligands for PPAR $\beta / \delta$ continue to be defined and include prostacyclin suggesting a potential role for $\mathrm{PPAR} \beta / \delta$ in regulation of vascular tone, platelet aggregation, and cell proliferation $[14,15]$. On the other hand, PPAR $\gamma$ ligands include the thiazolidinedione class of anti-diabetic medications (e.g. pioglitazone, rosiglitazone, and troglitazone), components of oxidized low-density lipoprotein [16], nitrated fatty acids (nitroalkenes), long chain fatty acids and their metabolites, and the $\mathrm{PGD}_{2}$ metabolite, 15 -deoxy- $\Delta 12$,14-prostglandin $\mathrm{J}_{2}$ $\left(15 \mathrm{~d}-\mathrm{PGJ} \mathrm{J}_{2}\right)$. However, despite this promiscuity for activating ligands and broad tissue distribution, specificity of PPARmediated tissue effects occurs, in part, through recruitment of ligand-specific populations of coactivator and corepressor molecules [17-19].

\section{PATHOGENESIS OF PULMONARY VASCULAR DYSFUNCTION}

The appreciation of the potential role of PPAR $\gamma$ in pulmonary vascular disease derives from several basic concepts of vascular disease pathogenesis. Current evidence indicates that endothelial dysfunction and derangements in the balanced production of vasodilatory and vasoconstrictive mediators play a critical role in both systemic $[20,21]$ and pulmonary vascular [22] diseases. Within the systemic circulation, endothelial dysfunction represents an early step in the pathogenesis of atherosclerotic vascular disease that culminates in coronary, peripheral vascular and cerebrovascular disease.

In contrast, pulmonary hypertension represents the most common manifestation of pulmonary vascular disease. Pulmonary hypertension is characterized by pulmonary vasoconstriction and vascular smooth muscle cell and endothelial cell proliferation. Defined as elevation of mean pulmonary artery pressure above $25 \mathrm{mmHg}$ at rest or above $30 \mathrm{mmHg}$ with exercise, pulmonary hypertension caused 15668 deaths and 260000 hospital visits in the United States in 2002 [23]. Pulmonary hypertension is most commonly caused by diverse clinical conditions that produce chronic continuous or intermittent alveolar hypoxia including chronic obstructive pulmonary disease, obstructive sleep apnea, or living at altitude. These conditions promote pulmonary vasoconstriction, vascular remodeling, and pulmonary hypertension. Less commonly, pulmonary hypertension develops secondary to congenital heart defects, autoimmune diseases, left-sided heart failure, or ingestion of certain anorexigen drugs or as a consequence of derangements in bone morphogenetic protein receptor signaling [24, 25]. Existing treatment strategies for patients with pulmonary hypertension are limited by an incomplete understanding of the underlying disease pathogenesis, high cost, and lack of efficacy indicating an urgent need for new approaches to our understanding and treatment of this disorder.

Abundant evidence in humans and animal models indicates that derangements in pulmonary endothelial-derived mediators and endothelial dysfunction play a pivotal role in pulmonary hypertension pathogenesis. Many of these endothelial mediators are also impacted by PPAR $\gamma$. The following summarizes what is known about the interplay between PPAR $y$ and these mediators.

\subsection{Nitric oxide}

Nitric oxide (NO) has been studied extensively as an endothelium-derived mediator that plays a critical role in normal vascular function and that promotes a host of vascular protective effects. For example, NO inhibits smooth muscle proliferation [26] and platelet aggregation [27], reduces endothelin-1 (ET-1) production [28], and protects against hypoxia-induced vasoconstriction [29]. Although chronic hypoxia causes pulmonary vasoconstriction through complex mechanisms, compelling evidence indicates that dysregulation of vascular endothelial function constitutes a critical event in the pathogenesis of pulmonary hypertension [22]. These endothelial derangements include alterations in the proliferative capacity of vascular endothelium as well as derangements in endothelium-derived mediators that modulate vascular smooth muscle cell function such as $\mathrm{NO}$, ET-1, serotonin, and prostanoids [30, 31]. While impaired NO bioavailability contributes to pulmonary hypertension $[32,33]$, the relationship between endothelial nitric oxide synthase (eNOS) expression and pulmonary hypertension is not clear as reports have variously described reduced, unchanged, or increased levels of the enzyme [34-37]. Perhaps this is not surprising given that eNOS-mediated NO production is regulated by complex mechanisms including co-factor availability [38-40], eNOS phosphorylation [4143], and protein-protein interactions [44-48]. Thus, pulmonary hypertension-associated alterations in these regulatory mechanisms as well as in eNOS expression determine rates of $\mathrm{NO}$ production in the pulmonary circulation.

Once NO is produced, its bioavailability can also be regulated by levels of other reactive targets in the surrounding vicinity. For example, superoxide reacts with $\mathrm{NO}$ at an extremely rapid, diffusion-limited rate to form the potent oxidant, peroxynitrite [49]. This reaction not only diverts NO from its generally salutary effects on physiological downstream signaling pathways but can simultaneously lead to oxidation of the eNOS cofactor, tetrahydrobiopterin, causing eNOS uncoupling and eNOS-mediated production of superoxide rather than NO $[50,51]$. These findings support evidence for impaired endothelium-derived, NO-mediated vasodilation in pulmonary hypertension [52]. The ability of NO inhalation to improve pulmonary hemodynamics and quality of life in selected patients with pulmonary hypertension [53] further suggests the importance of relative NO 
deficiency in this disorder. Collectively these and other studies indicate that post-translational alterations in eNOS regulation and/or enhanced NO degradation rather than reduced eNOS expression contribute significantly to pulmonary hypertension pathogenesis [38, 44, 46, 47].

NADPH oxidase is an important source of superoxide in pulmonary vasculature, and its stimulation by hypoxic conditions has been recognized for at least 10 years [54]. Recent publications have confirmed the importance of NADPH oxidase-derived reactive oxygen species in hypoxia-induced pulmonary hypertension. For example, in isolated-perfused lung preparations from wild-type mice, ventilation with $3 \%$ oxygen caused acute vasoconstrictor responses whereas hypoxic-induced vasoconstriction was blunted in NADPH oxidase deficient, p47phox knockout mice [55]. Similarly, $\mathrm{C} 57 \mathrm{Bl} / 6$ mice exposed to $10 \%$ oxygen for 3 weeks demonstrated increased superoxide generation in pulmonary arteries and increased right ventricular pressure and pulmonary arterial medial wall thickness [56]. These hypoxiainduced derangements were completely attenuated in similarly treated NADPH oxidase deficient, gp91 ${ }^{\text {phox }}$ knockout mice. In a separate report, these same investigators demonstrated that chronic hypoxia enhanced ET-1-stimulated pulmonary arterial vasoconstriction and superoxide generation and that these ET-1 effects were attenuated in gp91phox knockout mice [57]. NADPH oxidase appears to reside in both the endothelial and vascular smooth muscle cell compartments. Hypoxia stimulated superoxide generation in segments of intact pulmonary artery and in pulmonary artery endothelial or vascular smooth muscle cells ex vivo, and hypoxia-stimulated superoxide generation was inhibited by pharmacological inhibition of NADPH oxidase (with diphenyliodonium or apocynin) and was associated with enhanced gp91phox expression [47]. Taken together, these reports indicate that NADPH oxidase is an important mediator of pulmonary hypertension in response to hypoxia and that it contributes to enhanced vasoconstrictor responses in the pulmonary circulation following chronic hypoxia.

PPAR $\gamma$ ligands stimulate NO release from endothelial cells through PPAR $\gamma$-dependent signaling pathways $[58,59]$. This enhanced endothelial NO release was not related to increased eNOS expression $[58,59]$ but was mediated, in part, by alterations in the post-translational regulation of eNOS that increased enzyme activity [58]. PPAR $\gamma$ ligands also produced coordinate reductions in endothelial NADPH oxidase expression and activity and increased CuZn superoxide dismutase expression and activity $[60,61]$. Although additional studies will be required to confirm that these effects of PPAR $\gamma$ ligands on superoxide production and degradation are PPAR $\gamma$-dependent, these findings suggest that PPAR $\gamma$ ligands have great potential for favorably modulating NO bioavailability. Rosiglitazone-induced reductions in NADPH oxidase activity in a rat model of hypertension further support the potential of PPAR $\gamma$ ligands to favorably modulate dysregulated reactive oxygen species production [62]. Taken together, these findings suggest that PPAR $\gamma$ ligands can regulate the balance between endothelial NO and superoxide production and provide insights into potential mechanisms by which PPAR $\gamma$ ligands could reduce pulmonary endothelial dysfunction.

PPAR $y$ ligands also exert a variety of other effects on vascular wall cells that could be mediated, in part, by $\mathrm{NO}$ bioavailability. PPAR $\gamma$ ligands inhibit stimulated plasminogen activator inhibitor-1 production [63], inhibit smooth muscle cell migration and proliferation [64], and angiogenesis [65]. Nitroalkenes, the product of NO and unsaturated fatty acids, are potent endogenous PPAR $\gamma$ agonists that modulate PPAR $\gamma$-regulated signaling events such as adipogenesis and CD36 expression in macrophages [66]. Nitroalkenes also stimulate relaxation of vessel segments in an $\mathrm{NO}$-dependent manner [67] although their role in vascular regulation remains to be defined. Finally, in models of inflammation, $\operatorname{PPAR} \gamma$ ligands reduce inducible nitric oxide synthase expression [68], cytokine-induced monocyte chemotactic protein1 production [69], and endothelial-leukocyte adhesion [70]. Taken together, these reports illustrate that PPAR $\gamma$ plays a central role in regulating NO bioavailability and emphasize the potential relevance of PPAR $\gamma$ biology to both systemic and pulmonary vascular function.

\subsection{Endothelin-1}

ET-1 is a polypeptide that has been implicated in pulmonary hypertension pathogenesis. ET-1 is a potent vasoconstrictor that promotes platelet aggregation, and its receptors are upregulated in the lung in both animal models [71, 72] and patients with pulmonary hypertension [36]. ET-1, as well as endothelium-derived reactive oxygen species, attenuated NO-dependent pulmonary vasodilation following exposure to chronic hypoxia in isolated rat lungs [73]. ET-1induced pulmonary vasoconstriction was markedly reduced by administration of $\mathrm{Cu} / \mathrm{Zn}$ superoxide dismutase and was completely attenuated in gp91 ${ }^{\text {phox }}$ deficient mice [56]. These findings suggest that NADPH oxidase and superoxide play an important role in pulmonary vascular effects of ET-1.

Endothelin-1 receptor antagonists have been employed in patients with pulmonary hypertension to improve functional status and other indices of pulmonary hypertensionrelated morbidity [73], further suggesting that ET-1 is an important mediator of pulmonary vascular dysregulation. Limited evidence suggests that PPAR ligands inhibit ET-1 secretion by vascular endothelial cells $[74,75]$.

\subsection{Prostacyclin}

Prostacyclin, another endothelial-derived mediator involved in pulmonary vascular regulation, is a potent vasodilator that inhibits platelet aggregation and exerts anti-inflammatory, anti-thrombotic, and anti-proliferative vascular effects [76]. Overexpression of prostacyclin synthase protected mice from chronic hypoxia-induced pulmonary hypertension [77] whereas prostacyclin-receptor deficient mice were sensitized to hypoxia-induced pulmonary hypertension [78]. Decreased prostacyclin synthase expression has been noted in the pulmonary arteries of patients with severe pulmonary hypertension compared to normal subjects, and the 
vascular endothelium was found to be the major site of lung vascular prostacyclin synthase expression [34]. In patients with pulmonary hypertension, prostacyclin derivatives decreased urinary isoprostane metabolites, an index of oxidative stress without altering thromboxane A2 [79]. Currently, this endothelial-derived mediator is a therapeutic target in the treatment of pulmonary hypertension [80], however the precise cellular mechanisms responsible for prostacyclinmediated benefits remain to be defined.

Several studies have suggested potential relationships between PPAR, prostaglandin metabolism, and vascular disease. For example, inducible cyclooxygenase-2 (COX-2) is expressed in vascular endothelial cells and promotes vascular dysfunction [81-83]. The ability of PPAR $\gamma$ ligands to inhibit COX-2 induction [84] suggests potential relationships between PPAR $\gamma$ and altered prostaglandin metabolism in vascular dysfunction. PPAR $\beta / \delta$, a putative receptor for prostacyclin, was involved in prostacyclin-induced increases in endothelial cell survival [85] and has been implicated in the anti-thrombotic and anti-proliferative actions of prostacyclin $[14,15]$.

\subsection{Rho/rho kinase}

The small GTPase, Rho, and its associated effector, Rhokinase play a central role in diverse cellular functions including smooth muscle contraction, cell proliferation, and gene expression. Several studies have demonstrated that the Rho/Rho-kinase pathway participates in the pathogenesis of pulmonary hypertension. Rho-kinase activation was involved in hypoxia-induced pulmonary vasoconstriction [86] and increased basal pulmonary vascular tone in chronically hypoxic rats [87]. Rho-kinase inhibition reversed acute hypoxic vasoconstriction [88] and attenuated the development of chronic hypoxia-induced pulmonary hypertension and vascular remodeling in mice [89]. Long-term inhibition of Rho-kinase also prevented or reversed monocrotalineinduced pulmonary hypertension in rats by enhancing apoptosis and reducing proliferation of pulmonary artery smooth muscle cells [90]. Interestingly, inhaled Rho-kinase inhibitors caused selective pulmonary artery pressure reduction in several models of pulmonary hypertension [91]. Hypoxia-induced Rho-kinase activation may also contribute to capillary angiogenesis and sustained vasoconstriction [92]. Collectively, these data suggest that the Rho/Rho-kinase pathway represents an attractive therapeutic target in pulmonary hypertension.

Recent evidence demonstrated that PPAR $\gamma$ activation inhibited the Rho/Rho-kinase pathway through upregulation of the protein tyrosine phosphatase, SHP-2 [93]. The demonstration that PPAR $y$ ligands increased NO production $[58,59]$ and that NO increased SHP-2 activity and suppressed Rho/Rho kinase activation [94] provides additional evidence that this pathway may be amenable to manipulation with PPAR $\gamma$ ligands. Thus, the role of PPAR $\gamma$ in the regulation of the Rho/Rho-kinase pathway during pulmonary hypertension remains a promising area for continued investigation.

\section{PPAR $\gamma$ AND SYSTEMIC VASCULAR DISEASE}

To date, a more extensive literature has been devoted to investigation of PPAR $\gamma$ in the systemic than in the pulmonary circulation. In general, PPAR $\gamma$ activation attenuates endothelial dysfunction and the development of atherosclerosis. These findings are reviewed in brief to emphasize common pathways involved in PPAR $\gamma$-mediated regulation of vascular function. In vivo studies of atherosclerosis in non-diabetic mouse models, including low-density lipoprotein receptor or apolipoprotein E-deficient mice, demonstrated that thiazolidindione PPAR $\gamma$ ligands reduced lesion formation [9597] consistent with PPAR $\gamma$-mediated vascular protection in non-diabetic vascular disease. PPAR $\gamma$ activation also inhibited VEGF receptor expression and decreased endothelial tube formation in rats [65] as well as reduced VEGF and leptin-induced migration of human endothelial cells [98]. Another important step in the development of atherosclerosis involves adhesion of inflammatory cells to the endothelium. PPAR $\gamma$ activation decreased expression of several adhesion molecules, specifically VCAM and ICAM in endothelial cells [99] and reduced monocyte-endothelial cell interaction [70].

In addition, a growing body of literature in animal and human subjects indicates that PPAR $y$ ligand therapy is associated with improved endothelial function in vivo [100-103]. For example, pioglitazone and rosiglitazone decreased angiotensin II-induced hypertension and improved endothelium-dependent vasodilation in the rat [104]. Several mechanisms have been proposed for the antihypertensive effects of PPAR $\gamma$ ligands such as increased expression of PPAR $\gamma$ receptors in blood vessels [104], reduced expression of angiotensin II type I receptors [105], and more recently, direct inhibition of the Rho/Rho-kinase pathway [93]. In an ET-1-dependent hypertensive rat model, rosiglitazone restored endothelium-dependent vasodilation, diminished hypertension progression, and prevented vascular remodeling by decreasing ET-1 production and blunting production of reactive oxygen species [62]. Clinical data in diabetic subjects have demonstrated that thiazolidinedione PPAR $\gamma$ ligands: (a) reduced surrogate markers of vascular disease [101], (b) improved flow-mediated, endotheliumdependent vasodilation [102], and (c) reduced carotid intimal thickening [106] and neointimal formation after coronary stent placement [107]. The vascular protective effect of $\operatorname{PPAR} \gamma$ ligands in humans was recently extended to nondiabetic subjects with documented coronary disease; rosiglitazone reduced common carotid arterial intima-media thickness progression [108]. Moreover, in healthy, nondiabetic individuals, rosiglitazone significantly increased flow-mediated endothelium-dependent vasodilation as well as reduced inflammatory biomarkers of atherosclerosis [109]. Finally, pioglitazone improved endothelial-dependent dilation in nondiabetic patients with cardiovascular risk factors [110]. Large clinical trials are currently underway that will ultimately determine if thiazolidinediones alter systemic vascular outcomes in patients with and without diabetes. 


\section{PPAR $\gamma$ AND PULMONARY HYPERTENSION}

Several studies have suggested a potential role for PPAR $\gamma$ in the pathogenesis of pulmonary hypertension. For example, PPAR $\gamma$ is abundantly expressed in pulmonary vascular endothelial cells of normal human lung tissue and is significantly reduced in the plexiform lesions of human subjects with pulmonary hypertension [111]. Reduced PPAR $\gamma$ expression was also demonstrated in vascular lesions of a rat model of severe pulmonary hypertension caused by treatment with a VEGF receptor inhibitor in combination with hypobaric hypoxia exposure [111]. Furthermore, loss of PPAR $y$ expression resulted in abnormal proliferation of apoptosis-resistant endothelial cells. The causal link between apoptosis and pulmonary hypertension-associated alterations in PPAR $\gamma$ expression remains to be established. However, additional evidence that vascular endothelial cell apoptosis is induced by overexpression of PPAR $\gamma$ or by treatment with $15 \mathrm{~d}-\mathrm{PGJ}_{2}$ suggests fertile areas for future investigation [112]. Hypoxia as well as shear stress were implicated in reduced PPAR $\gamma$ expression in human endotheliallike cell lines [111]. Because oscillatory shear stress downregulates eNOS and upregulates ET-1 [113] and NADPH oxidase $[114,115]$, these findings suggest that the hemodynamic derangements in pulmonary hypertension may contribute to the development or propagation of vascular dysfunction and that reductions in PPAR $y$ expression during pulmonary hypertension may lead to dysregulated production of a broad variety of vascular mediators that contribute to pulmonary vascular remodeling and pulmonary hemodynamic dysfunction.

Not only does pulmonary hypertension appear to be associated with reduced PPAR $\gamma$ expression, emerging evidence suggests that ligand-induced PPAR $\gamma$ activation attenuates pulmonary vascular dysfunction in animal models of pulmonary hypertension. For example, PPAR $\gamma$ activation with either pioglitazone or troglitazone significantly reduced pulmonary hypertension and pulmonary artery wall thickening in a rat model of monocrotaline-induced pulmonary hypertension [116]. Although the exact mechanisms by which PPAR $y$ exerts its effects in pulmonary hypertension remain to be defined, several studies have shown that PPAR $\gamma$ activation reduced proliferation of vascular smooth muscle cells and promoted apoptosis in several cell lines in vitro [117, 118]. Murine models of pulmonary hypertension are characterized more by medial thickening of the pulmonary vasculature and lack the characteristic plexiform lesions composed of proliferative intraluminal endothelial cells that characterize human pulmonary hypertension [119]. These reports indicate that attenuation of monocrotaline-induced pulmonary hypertension may well be related to the capacity of PPAR $\gamma$ activation to inhibit vascular smooth muscle cell proliferation [116].

PPAR $\gamma$ ligands also attenuated hypoxia-induced pulmonary hypertension. Treatment with rosiglitazone reduced hypoxia-induced pulmonary artery remodeling in WistarKyoto rats [120]. In this study rats were randomized to normoxia or hypobaric hypoxia and treated with rosiglitazone
( $2.5 \mathrm{mg} / \mathrm{kg} /$ day) for 3 weeks. Rosiglitazone decreased right ventricular hypertrophy and pulmonary arterial remodeling. Moreover, these changes were attributed to the inhibition of smooth muscle proliferation and were not associated with increased apoptosis further supporting previous findings in the monocrotaline-induced pulmonary hypertension model.

While little is known about the involvement of $\mathrm{PPAR} \beta / \delta$ in pulmonary hypertension, recent data suggest that $\operatorname{PPAR} \beta / \delta$ could be a potential therapeutic target. PPAR $\beta / \delta$ was activated by prostacyclin [15] suggesting that the beneficial effects of prostacyclin therapy, the current treatment of choice for many patients with severe pulmonary hypertension, could be mediated in part through activation of $\operatorname{PPAR} \beta / \delta$. Additionally, treprostinil sodium, a prostacylin mimetic, activated $\operatorname{PPAR} \beta / \delta$ and inhibited proliferation of human lung fibroblasts at concentrations consistent with a PPAR rather than a prostacyclin receptor-mediated pathway [15]. These limited observations suggest that PPAR $\beta / \delta$ deserves additional study as a potential therapeutic target for treatment of pulmonary hypertension.

\section{FUTURE DIRECTIONS AND CONCLUSIONS}

In unpublished data, we have observed that exposure to chronic hypoxia (10\% oxygen) for 3 weeks reduced lung PPAR $\gamma$ expression and caused pulmonary hypertension in $\mathrm{C} 57 \mathrm{Bl} / 6$ mice as indicated by elevation of right ventricular systolic pressure and right ventricular hypertrophy. Treatment with rosiglitazone $(10 \mathrm{mg} / \mathrm{kg} /$ day $)$ by gavage during the final 10 days of this hypoxia exposure regimen attenuated pulmonary hypertension and right ventricular hypertrophy. Hypoxia-induced pulmonary hypertension was also associated with reductions in serum levels of nitrosylhemoglobin (NO-Hgb), an index of NO bioavailability. Hypoxia-induced alterations in NO bioavailability were not associated with lower eNOS protein levels. These preliminary findings further support the hypothesis that ligand-induced PPAR $\gamma$ activation attenuates hypoxia-induced reductions in NO bioavailability in part by suppressing the generation of reactive oxygen species that inactivate $\mathrm{NO}$ such as superoxide $[61,120,121]$ and in part by promoting eNOS activity through modification of post-translational regulatory mechanisms [58]. Taken together, these findings suggest that PPAR $\gamma$ may represent a novel potential therapeutic target in pulmonary hypertension that modulates nitroso-redox balance in the vasculature. The relationships between PPAR $\gamma$ and selected aspects of endothelial dysfunction in pulmonary hypertension are schematically presented in Figure 1.

Current evidence strongly suggests that vascular endothelial dysregulation plays a crucial role in the initiation and progression of pulmonary hypertension. Moreover, alterations in endothelium-derived mediators such as NO, ET1 , and prostanoids as well as reactive oxygen species have been established as important mechanisms in the development of vascular remodeling leading to pulmonary hypertension. Our understanding of PPAR $\gamma$ biology has progressed rapidly over the last decade but much remains to be learned about the mechanisms by which these receptors and 


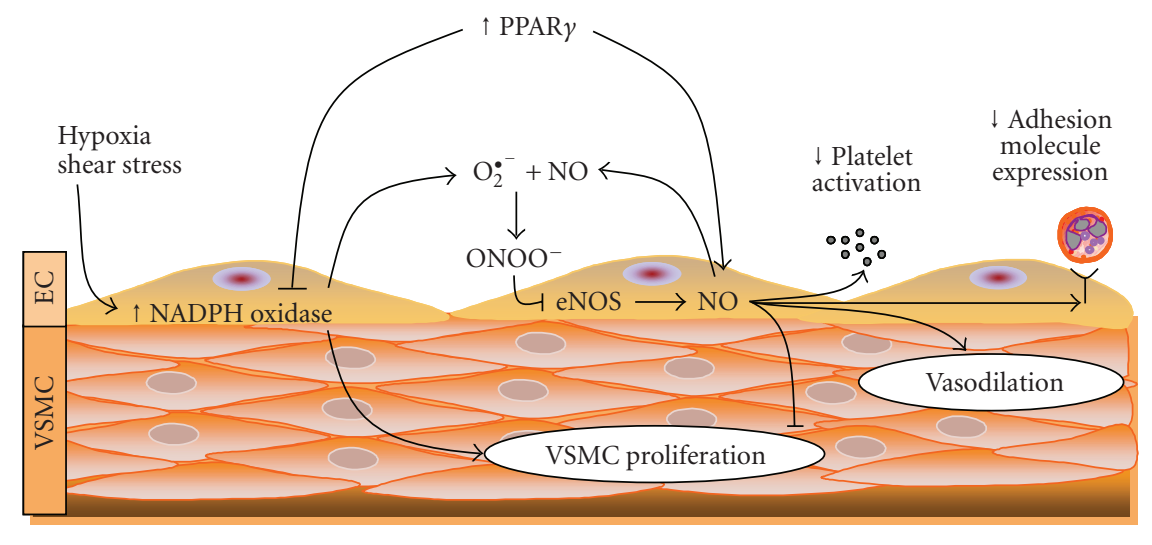

FIGURE 1: The effects of PPAR y activation on reactive oxygen species and nitric oxide production in the vascular wall. Factors including hypoxia and shear stress increase the production of superoxide in the vascular wall by NADPH oxidase. Superoxide $\left(\mathrm{O}_{2}^{-}\right)$rapidly reacts with nitric oxide (NO) generated by endothelial nitric oxide synthase (eNOS) to reduce the bioavailability of NO to stimulate vasodilation and inhibit vascular smooth muscle cell (VSMC) proliferation, platelet activation, and adhesion molecule expression. PPAR $\gamma$ activation inhibits NADPH oxidase expression and activity [61] and stimulates NO production in vascular endothelial cells (EC) [58, 59]. These effects illustrate potential mechanisms by which PPAR $\gamma$ activation may favorably modulate pulmonary endothelial dysfunction and pulmonary hypertension.

their ligands regulate the pulmonary vasculature. Identifying specific downstream targets regulated by PPARs in the pulmonary vasculature will facilitate the development of potential PPAR-related therapeutic strategies for the prevention or treatment of pulmonary hypertension.

\section{ACKNOWLEDGMENTS}

The authors wish to acknowledge their grant support from the Veterans Affairs Research Service, the National Institutes of Health, and Takeda Pharmaceuticals.

\section{REFERENCES}

[1] I. Issemann and S. Green, "Activation of a member of the steroid hormone receptor superfamily by peroxisome proliferators," Nature, vol. 347, no. 6294, pp. 645-650, 1990.

[2] A. J. Gilde, K. A. J. M. van der Lee, P. H. M. Willemsen, et al., "Peroxisome proliferator-activated receptor (PPAR) $\alpha$ and $\operatorname{PPAR} \beta / \delta$, but not $\operatorname{PPAR} \gamma$, modulate the expression of genes involved in cardiac lipid metabolism," Circulation Research, vol. 92, no. 5, pp. 518-524, 2003.

[3] I. Saluja, J. G. Granneman, and R. P. Skoff, "PPAR $\delta$ agonists stimulate oligodendrocyte differentiation in tissue culture," GLIA, vol. 33, no. 3, pp. 191-204, 2001.

[4] Y. Barak, D. Liao, W. He, et al., "Effects of peroxisome proliferator-activated receptor $\delta$ on placentation, adiposity, and colorectal cancer," Proceedings of the National Academy of Sciences of the United States of America, vol. 99, no. 1, pp. 303-308, 2002.

[5] N. S. Tan, L. Michalik, B. Desvergne, and W. Wahli, "Multiple expression control mechanisms of peroxisome proliferatoractivated receptors and their target genes," Journal of Steroid Biochemistry and Molecular Biology, vol. 93, no. 2-5, pp. 99105, 2005.

[6] C.-H. Lee, A. Chawla, N. Urbiztondo, D. Liao, W. A. Boisvert, R. M. Evans, and L. K. Curtiss, "Transcriptional repression of atherogenic inflammation: modulation by $\operatorname{PPAR} \delta$," Science, vol. 302, no. 5644, pp. 453-457, 2003.

[7] G. Chinetti, S. Griglio, M. Antonucci, et al., "Activation of proliferator-activated receptors $\alpha$ and $\gamma$ induces apoptosis of human monocyte-derived macrophages," Journal of Biological Chemistry, vol. 273, no. 40, pp. 25573-25580, 1998.

[8] R. A. Daynes and D. C. Jones, "Emerging roles of PPARs in inflammation and immunity," Nature Reviews Immunology, vol. 2, no. 10, pp. 748-759, 2002.

[9] V. G. Keshamouni, D. A. Arenberg, R. C. Reddy, M. J. Newstead, S. Anthwal, and T. J. Standiford, "PPAR- $\gamma$ activation inhibits angiogenesis by blocking ELR+CXC chemokine production in non-small cell lung cancer," Neoplasia, vol. 7, no. 3, pp. 294-301, 2005.

[10] V. G. Keshamouni, R. C. Reddy, D. A. Arenberg, et al., "Peroxisome proliferator-activated receptor- $\gamma$ activation inhibits tumor progression in non-small-cell lung cancer," Oncogene, vol. 23, no. 1, pp. 100-108, 2004.

[11] K. L. Gearing, M. Gottlicher, M. Teboul, E. Widmark, and J.A. Gustafsson, "Interaction of the peroxisome-proliferatoractivated receptor and retinoid X receptor," Proceedings of the National Academy of Sciences of the United States of America, vol. 90, no. 4, pp. 1440-1444, 1993.

[12] E. D. Rosen and B. M. Spiegelman, "PPAR $\gamma$ : a nuclear regulator of metabolism, differentiation, and cell growth," Journal of Biological Chemistry, vol. 276, no. 41, pp. 37731-37734, 2001.

[13] H. E. Xu, T. B. Stanley, V. G. Montana, et al., "Structural basis for antagonist-mediated recruitment of nuclear corepressors by PPAR $\alpha$," Nature, vol. 415, no. 6873, pp. 813$817,2002$.

[14] F. Y. Ali, S. J. Davidson, L. A. Moraes, et al., "Role of nuclear receptor signaling in platelets: antithrombotic effects of PPAR $\beta$," The FASEB Journal, vol. 20, no. 2, pp. 326-328, 2006.

[15] F. Y. Ali, K. Egan, G. A. FitzGerald, et al., "Role of prostacyclin versus peroxisome proliferator-activated receptor $\beta$ receptors in prostacyclin sensing by lung fibroblasts," American Journal of Respiratory Cell and Molecular Biology, vol. 34, no. 2, pp. 242-246, 2006. 
[16] P. Tontonoz, L. Nagy, J. G. A. Alvarez, V. A. Thomazy, and R. M. Evans, "PPAR $\gamma$ promotes monocyte/macrophage differentiation and uptake of oxidized LDL," Cell, vol. 93, no. 2, pp. 241-252, 1998.

[17] H. S. Camp, O. Li, S. C. Wise, et al., "Differential activation of peroxisome proliferator-activated receptor- $\gamma$ by troglitazone and rosiglitazone," Diabetes, vol. 49, no. 4, pp. 539-547, 2000.

[18] Y. Kodera, K.-I. Takeyama, A. Murayama, M. Suzawa, Y. Masuhiro, and S. Kato, "Ligand type-specific interactions of peroxisome proliferator-activated receptor $\gamma$ with transcriptional coactivators," Journal of Biological Chemistry, vol. 275, no. 43, pp. 33201-33204, 2000.

[19] J. M. Olefsky, "Treatment of insulin resistance with peroxisome proliferator-activated receptor $\gamma$ agonists," Journal of Clinical Investigation, vol. 106, no. 4, pp. 467-472, 2000.

[20] M. A. Haidara, H. Z. Yassin, M. Rateb, H. Ammar, and M. A. Zorkani, "Role of oxidative stress in development of cardiovascular complications in diabetes mellitus," Current Vascular Pharmacology, vol. 4, no. 3, pp. 215-227, 2006.

[21] R. E. Schmieder, "Endothelial dysfunction: how can one intervene at the beginning of the cardiovascular continuum?" Journal of Hypertension, vol. 24, supplement 2, pp. S31-S35, 2006.

[22] R. Budhiraja, R. M. Tuder, and P. M. Hassoun, "Endothelial dysfunction in pulmonary hypertension," Circulation, vol. 109, no. 2, pp. 159-165, 2004.

[23] A. Hyduk, J. B. Croft, C. Ayala, K. Zheng, Z. J. Zheng, and G. A. Mensah, "Pulmonary hypertension surveillance-United States, 1980-2002," Morbidity and Mortality Weekly Report, vol. 54, no. 5, pp. 1-28, 2005.

[24] L. Du, C. C. Sullivan, D. Chu, et al., "Signaling molecules in nonfamilial pulmonary hypertension," The New England Journal of Medicine, vol. 348, no. 6, pp. 500-509, 2003.

[25] J. H. Newman, L. Wheeler, K. B. Lane, et al., "Mutation in the gene for bone morphogenetic protein receptor II as a cause of primary pulmonary hypertension in a large kindred," The New England Journal of Medicine, vol. 345, no. 5, pp. 319-324, 2001.

[26] U. C. Garg and A. Hassid, "Nitric oxide-generating vasodilators and 8-bromo-cyclic guanosine monophosphate inhibit mitogenesis and proliferation of cultured rat vascular smooth muscle cells," Journal of Clinical Investigation, vol. 83, no. 5, pp. 1774-1777, 1989.

[27] H. Azuma, M. Ishikawa, and S. Sekizaki, "Endotheliumdependent inhibition of platelet aggregation," British Journal of Pharmacology, vol. 88, no. 2, pp. 411-415, 1986.

[28] A. P. L. Smith, E. A. G. Demoncheaux, and T. W. Higenbottam, "Nitric oxide gas decreases endothelin-1 mRNA in cultured pulmonary artery endothelial cells," Nitric Oxide, vol. 6, no. 2, pp. 153-159, 2002.

[29] M. A. Perrella, E. S. Edell, M. J. Krowka, D. A. Cortese, and J. C. Burnett Jr., "Endothelium-derived relaxing factor in pulmonary and renal circulations during hypoxia," American Journal of Physiology, vol. 263, no. 1, part 2, pp. R45-R50, 1992.

[30] F. Ichinose, R. Ullrich, A. Sapirstein, et al., "Cytosolic phospholipase $\mathrm{A}_{2}$ in hypoxic pulmonary vasoconstriction," Journal of Clinical Investigation, vol. 109, no. 11, pp. 1493-1500, 2002.

[31] J. Wang, M. Juhaszova, L. J. Rubin, and X.-J. Yuan, "Hypoxia inhibits gene expression of voltage-gated $\mathrm{K}^{+}$channel $\alpha$ subunits in pulmonary artery smooth muscle cells," Journal of Clinical Investigation, vol. 100, no. 9, pp. 2347-2353, 1997.
[32] S. Adnot, B. Raffestin, S. Eddahibi, P. Braquet, and P.-E. Chabrier, "Loss of endothelium-dependent relaxant activity in the pulmonary circulation of rats exposed to chronic hypoxia," Journal of Clinical Investigation, vol. 87, no. 1, pp. 155-162, 1991.

[33] R. H. Steinhorn, J. A. Russell, S. Lakshminrusimha, S. F. Gugino, S. M. Black, and J. R. Fineman, "Altered endotheliumdependent relaxations in lambs with high pulmonary blood flow and pulmonary hypertension," American Journal of Physiology, vol. 280, no. 1, pp. H311-H317, 2001.

[34] R. M. Tuder, C. D. Cool, M. W. Geraci, et al., "Prostacyclin synthase expression is decreased in lungs from patients with severe pulmonary hypertension," American Journal of Respiratory and Critical Care Medicine, vol. 159, no. 6, pp. 19251932, 1999.

[35] L. P. McQuillan, G. K. Leung, P. A. Marsden, S. K. Kostyk, and S. Kourembanas, "Hypoxia inhibits expression of eNOS via transcriptional and posttranscriptional mechanisms," American Journal of Physiology, vol. 267, no. 5, part 2, pp. H1921H1927, 1994.

[36] A. Giaid and D. Saleh, "Reduced expression of endothelial nitric oxide synthase in the lungs of patients with pulmonary hypertension," The New England Journal of Medicine, vol. 333, no. 4, pp. 214-221, 1995.

[37] C. Xue and R. A. Johns, "Endothelial nitric oxide synthase in the lungs of patients with pulmonary hypertension," The New England Journal of Medicine, vol. 333, no. 24, pp. 1642-1644, 1995.

[38] J. P. Khoo, L. Zhao, N. J. Alp, et al., "Pivotal role for endothelial tetrahydrobiopterin in pulmonary hypertension," Circulation, vol. 111, no. 16, pp. 2126-2133, 2005.

[39] M. Nandi, A. Miller, R. Stidwill, et al., "Pulmonary hypertension in a GTP-cyclohydrolase 1-deficient mouse," Circulation, vol. 111, no. 16, pp. 2086-2090, 2005.

[40] P. Rosenkranz-Weiss, W. C. Sessa, S. Milstien, S. Kaufman, C. A. Watson, and J. S. Pober, "Regulation of nitric oxide synthesis by proinflammatory cytokines in human umbilical vein endothelial cells. Elevations in tetrahydrobiopterin levels enhance endothelial nitric oxide synthase specific activity," Journal of Clinical Investigation, vol. 93, no. 5, pp. 22362243, 1994.

[41] S. Dimmeler, I. Fleming, B. Fisslthaler, C. Hermann, R. Busse, and A. M. Zeiher, "Activation of nitric oxide synthase in endothelial cells by Akt-dependent phosphorylation," Nature, vol. 399, no. 6736, pp. 601-605, 1999.

[42] D. Fulton, J.-P. Gratton, T. J. McCabe, et al., "Regulation of endothelium-derived nitric oxide production by the protein kinase Akt," Nature, vol. 399, no. 6736, pp. 597-601, 1999.

[43] T. Murata, M. Hori, K. Sakamoto, H. Karaki, and H. Ozaki, "Dexamethasone blocks hypoxia-induced endothelial dysfunction in organ-cultured pulmonary arteries," American Journal of Respiratory and Critical Care Medicine, vol. 170, no. 6, pp. 647-655, 2004.

[44] G. G. Konduri, J. Ou, Y. Shi, and K. A. Pritchard Jr., "Decreased association of HSP90 impairs endothelial nitric oxide synthase in fetal lambs with persistent pulmonary hypertension," American Journal of Physiology, vol. 285, no. 1, pp. H204-H211, 2003.

[45] G. García-Cardeña, R. Fan, V. Shah, et al., "Dynamic activation of endothelial nitric oxide synthase by Hsp90," Nature, vol. 392, no. 6678, pp. 821-824, 1998.

[46] T. Murata, K. Sato, M. Hori, H. Ozaki, and H. Karaki, "Decreased endothelial nitric-oxide synthase (eNOS) activity resulting from abnormal interaction between eNOS and its 
regulatory proteins in hypoxia-induced pulmonary hypertension," Journal of Biological Chemistry, vol. 277, no. 46, pp. 44085-44092, 2002.

[47] S. Muzaffar, N. Shukla, G. D. Angelini, and J. Y. Jeremy, "Acute hypoxia simultaneously induces the expression of gp91 ${ }^{\text {phox }}$ and endothelial nitric oxide synthase in the porcine pulmonary artery," Thorax, vol. 60, no. 4, pp. 305-313, 2005.

[48] K. A. Pritchard Jr., A. W. Ackerman, E. R. Gross, et al., "Heat shock protein 90 mediates the balance of nitric oxide and superoxide anion from endothelial nitric-oxide synthase," Journal of Biological Chemistry, vol. 276, no. 21, pp. 17621-17624, 2001.

[49] J. S. Beckman and W. H. Koppenol, "Nitric oxide, superoxide, and peroxynitrite: the good, the bad, and the ugly," American Journal of Physiology, vol. 271, no. 5, part 1, pp. C1424C1437, 1996.

[50] N. Kuzkaya, N. Weissmann, D. G. Harrison, and S. Dikalov, "Interactions of peroxynitrite, tetrahydrobiopterin, ascorbic acid, and thiols: implications for uncoupling endothelial nitric-oxide synthase," Journal of Biological Chemistry, vol. 278, no. 25, pp. 22546-22554, 2003.

[51] U. Landmesser, S. Dikalov, S. R. Price, et al., "Oxidation of tetrahydrobiopterin leads to uncoupling of endothelial cell nitric oxide synthase in hypertension," Journal of Clinical Investigation, vol. 111, no. 8, pp. 1201-1209, 2003.

[52] S. Mehta, D. J. Stewart, D. Langleben, and R. D. Levy, "Shortterm pulmonary vasodilation with L-arginine in pulmonary hypertension," Circulation, vol. 92, no. 6, pp. 1539-1545, 1995.

[53] R. N. Channick, J. W. Newhart, F. W. Johnson, et al., "Pulsed delivery of inhaled nitric oxide to patients with primary pulmonary hypertension: an ambulatory delivery system and initial clinical tests," Chest, vol. 109, no. 6, pp. 1545-1549, 1996.

[54] C. Marshall, A. J. Mamary, A. J. Verhoeven, and B. E. Marshall, "Pulmonary artery NADPH-oxidase is activated in hypoxic pulmonary vasoconstriction," American Journal of Respiratory Cell and Molecular Biology, vol. 15, no. 5, pp. 633644, 1996.

[55] N. Weissmann, S. Zeller, R. U. Schäfer, et al., "Impact of mitochondria and NADPH oxidases on acute and sustained hypoxic pulmonary vasoconstriction," American Journal of Respiratory Cell and Molecular Biology, vol. 34, no. 4, pp. 505513, 2006

[56] J. Q. Liu, I. N. Zelko, E. M. Erbynn, J. S. K. Sham, and R. J. Folz, "Hypoxic pulmonary hypertension: role of superoxide and NADPH oxidase (gp91 $\left.{ }^{\text {phox }}\right)$," American Journal of Physiology, vol. 290, no. 1, pp. L2-L10, 2006.

[57] J. Q. Liu, E. M. Erbynn, and R. J. Folz, "Chronic hypoxiaenhanced murine pulmonary vasoconstriction: role of superoxide and gp91 ${ }^{\text {phox }, " ~ C h e s t, ~ v o l . ~ 128, ~ n o . ~} 6$ supplement, pp. 594S-596S, 2005.

[58] J. A. Polikandriotis, L. J. Mazzella, H. L. Rupnow, and C. M. Hart, "Peroxisome proliferator-activated receptor $\gamma$ ligands stimulate endothelial nitric oxide production through distinct peroxisome proliferator-activated receptor $\gamma$-dependent mechanisms," Arteriosclerosis, Thrombosis, and Vascular Biology, vol. 25, no. 9, pp. 1810-1816, 2005.

[59] D. S. Calnek, L. J. Mazzella, S. Roser, J. Roman, and C. M. Hart, "Peroxisome proliferator-activated receptor $\gamma$ ligands increase release of nitric oxide from endothelial cells," Arteriosclerosis, Thrombosis, and Vascular Biology, vol. 23, no. 1, pp. 52-57, 2003.
[60] I. Inoue, S.-I. Goto, T. Matsunaga, et al., "The ligands/activators for peroxisome proliferator-activated receptor $\alpha(\operatorname{PPAR} \alpha)$ and PPAR $\gamma$ increase $\mathrm{Cu}^{2+}, \mathrm{Zn}^{2+}$-superoxide dismutase and decrease $\mathrm{p} 22$ phox message expressions in primary endothelial cells," Metabolism, vol. 50, no. 1, pp. 3-11, 2001.

[61] J. Hwang, D. J. Kleinhenz, B. Lasségue, K. K. Griendling, S. Dikalov, and C. M. Hart, "Peroxisome proliferator-activated receptor- $\gamma$ ligands regulate endothelial membrane superoxide production," American Journal of Physiology, vol. 288, no. 4, pp. C899-C905, 2005.

[62] M. Iglarz, R. M. Touyz, F. Amiri, M.-F. Lavoie, Q. N. Diep, and E. L. Schiffrin, "Effect of peroxisome proliferatoractivated receptor- $\alpha$ and $-\gamma$ activators on vascular remodeling in endothelin-dependent hypertension," Arteriosclerosis, Thrombosis, and Vascular Biology, vol. 23, no. 1, pp. 45-51, 2003.

[63] K. Kato, H. Satoh, Y. Endo, et al., "Thiazolidinediones downregulate plasminogen activator inhibitor type 1 expression in human vascular endothelial cells: a possible role for PPAR $\gamma$ in endothelial function," Biochemical and Biophysical Research Communications, vol. 258, no. 2, pp. 431-435, 1999.

[64] R. E. Law, W. P. Meehan, X.-P. Xi, et al., "Troglitazone inhibits vascular smooth muscle cell growth and intimal hyperplasia," Journal of Clinical Investigation, vol. 98, no. 8, pp. 1897-1905, 1996.

[65] X. Xin, S. Yang, J. Kowalski, and M. E. Gerritsen, "Peroxisome proliferator-activated receptor $\gamma$ ligands are potent inhibitors of angiogenesis in vitro and in vivo," Journal of Biological Chemistry, vol. 274, no. 13, pp. 9116-9121, 1999.

[66] F. J. Schopfer, Y. Lin, P. R. S. Baker, et al., "Nitrolinoleic acid: an endogenous peroxisome proliferator-activated receptor $\gamma$ ligand," Proceedings of the National Academy of Sciences of the United States of America, vol. 102, no. 7, pp. 2340-2345, 2005.

[67] T. Cui, F. J. Schopfer, J. Zhang, et al., "Nitrated fatty acids: endogenous anti-inflammatory signaling mediators," Journal of Biological Chemistry, vol. 281, no. 47, pp. 35686-35698, 2006.

[68] U. Ikeda, M. Shimpo, Y. Murakami, and K. Shimada, "Peroxisome proliferator-activated receptor- $\gamma$ ligands inhibit nitric oxide synthesis in vascular smooth muscle cells," Hypertension, vol. 35, no. 6, pp. 1232-1236, 2000.

[69] K. Murao, H. Imachi, A. Momoi, et al., "Thiazolidinedione inhibits the production of monocyte chemoattractant protein-1 in cytokine-treated human vascular endothelial cells," FEBS Letters, vol. 454, no. 1-2, pp. 27-30, 1999.

[70] S. M. Jackson, F. Parhami, X.-P. Xi, et al., "Peroxisome proliferator-activated receptor activators target human endothelial cells to inhibit leukocyte-endothelial cell interaction," Arteriosclerosis, Thrombosis, and Vascular Biology, vol. 19, no. 9, pp. 2094-2104, 1999.

[71] H. F. Frasch, C. Marshall, and B. E. Marshall, "Endothelin-1 is elevated in monocrotaline pulmonary hypertension," American Journal of Physiology, vol. 276, no. 2, part 1, pp. L304L310, 1999.

[72] H. Li, S.-J. Chen, Y.-F. Chen, et al., "Enhanced endothelin-1 and endothelin receptor gene expression in chronic hypoxia," Journal of Applied Physiology, vol. 77, no. 3, pp. 1451-1459, 1994.

[73] N. L. Jernigan, B. R. Walker, and T. C. Resta, "Endotheliumderived reactive oxygen species and endothelin-1 attenuate NO-dependent pulmonary vasodilation following chronic hypoxia," American Journal of Physiology, vol. 287, no. 4, pp. L801-L808, 2004. 
[74] P. Delerive, F. Martin-Nizard, G. Chinetti, et al., "Peroxisome proliferator-activated receptor activators inhibit thrombininduced endothelin-1 production in human vascular endothelial cells by inhibiting the activator protein-1 signaling pathway," Circulation Research, vol. 85, no. 5, pp. 394-402, 1999.

[75] F. Martin-Nizard, C. Furman, P. Delerive, et al., "Peroxisome proliferator-activated receptor activators inhibit oxidized low-density lipoprotein-induced endothelin-1 secretion in endothelial cells," Journal of Cardiovascular Pharmacology, vol. 40, no. 6, pp. 822-831, 2002.

[76] H. Olschewski, F. Rose, R. Schermuly, et al., "Prostacyclin and its analogues in the treatment of pulmonary hypertension," Pharmacology and Therapeutics, vol. 102, no. 2, pp. 139-153, 2004.

[77] M. W. Geraci, B. Gao, D. C. Shepherd, et al., "Pulmonary prostacyclin synthase overexpression in transgenic mice protects against development of hypoxic pulmonary hypertension," Journal of Clinical Investigation, vol. 103, no. 11, pp. 1509-1515, 1999.

[78] Y. Hoshikawa, N. F. Voelkel, T. L. Gesell, et al., "Prostacyclin receptor-dependent modulation of pulmonary vascular remodeling," American Journal of Respiratory and Critical Care Medicine, vol. 164, no. 2, pp. 314-318, 2001.

[79] I. M. Robbins, J. D. Morrow, and B. W. Christman, "Oxidant stress but not thromboxane decreases with epoprostenol therapy," Free Radical Biology and Medicine, vol. 38, no. 5, pp. 568-574, 2005.

[80] E. B. Rosenzweig and R. J. Barst, "Pulmonary arterial hypertension: a comprehensive review of pharmacological treatment," Treatments in Respiratory Medicine, vol. 5, no. 2, pp. 117-127, 2006.

[81] D. Bishop-Bailey, "Peroxisome proliferator-activated receptors in the cardiovascular system," British Journal of Pharmacology, vol. 129, no. 5, pp. 823-834, 2000.

[82] M. E. Burleigh, V. R. Babaev, J. A. Oates, et al., "Cyclooxygenase-2 promotes early atherosclerotic lesion formation in LDL receptor-deficient mice," Circulation, vol. 105, no. 15, pp. 1816-1823, 2002.

[83] R. E. Law, S. Goetze, X.-P. Xi, et al., "Expression and function of PPAR $y$ in rat and human vascular smooth muscle cells," Circulation, vol. 101, no. 11, pp. 1311-1318, 2000.

[84] K. Subbaramaiah, D. T. Lin, J. C. Hart, and A. J. Dannenberg, "Peroxisome proliferator-activated receptor $\gamma$ ligands suppress the transcriptional activation of cyclooxygenase2. Evidence for involvement of activator protein-1 and CREB-binding protein/p300," Journal of Biological Chemistry, vol. 276, no. 15, pp. 12440-12448, 2001.

[85] J.-Y. Liou, S. Lee, D. Ghelani, N. Matijevic-Aleksic, and K. $\mathrm{K}$. Wu, "Protection of endothelial survival by peroxisome proliferator-activated receptor- $\delta$ mediated 14-3-3 upregulation," Arteriosclerosis, Thrombosis, and Vascular Biology, vol. 26, no. 7, pp. 1481-1487, 2006.

[86] Z. Wang, N. Jin, S. Ganguli, D. R. Swartz, L. Li, and R. A. Rhoades, "Rho-kinase activation is involved in hypoxiainduced pulmonary vasoconstriction," American Journal of Respiratory Cell and Molecular Biology, vol. 25, no. 5, pp. 628$635,2001$.

[87] T. Nagaoka, Y. Morio, N. Casanova, et al., "Rho/Rho-kinase signaling mediates increased basal pulmonary vascular tone in chronically hypoxic rats," American Journal of Physiology, vol. 287, no. 4, pp. L665-L672, 2004.
[88] T. P. Robertson, M. Dipp, J. P. T. Ward, P. I. Aaronson, and A. M. Evans, "Inhibition of sustained hypoxic vasoconstriction by Y-27632 in isolated intrapulmonary arteries and perfused lung of the rat," British Journal of Pharmacology, vol. 131, no. 1, pp. 5-9, 2000.

[89] K. A. Fagan, M. Oka, N. R. Bauer, et al., "Attenuation of acute hypoxic pulmonary vasoconstriction and hypoxic pulmonary hypertension in mice by inhibition of Rho-kinase," American Journal of Physiology, vol. 287, no. 4, pp. L656L664, 2004.

[90] K. Abe, H. Shimokawa, K. Morikawa, et al., "Longterm treatment with a Rho-kinase inhibitor improves monocrotaline-induced fatal pulmonary hypertension in rats," Circulation Research, vol. 94, no. 3, pp. 385-393, 2004.

[91] T. Nagaoka, K. A. Fagan, S. A. Gebb, et al., "Inhaled Rhokinase inhibitors are potent and selective vasodilators in rat pulmonary hypertension," American Journal of Respiratory and Critical Care Medicine, vol. 171, no. 5, pp. 494-499, 2005.

[92] J.-M. Hyvelin, K. Howell, A. Nichol, C. M. Costello, R. J. Preston, and P. McLoughlin, "Inhibition of Rho-kinase attenuates hypoxia-induced angiogenesis in the pulmonary circulation," Circulation Research, vol. 97, no. 2, pp. 185-191, 2005.

[93] S. Wakino, K. Hayashi, T. Kanda, et al., "Peroxisome proliferator-activated receptor $\gamma$ ligands inhibit Rho/Rhokinase pathway by inducing protein tyrosine phosphatase SHP-2," Circulation Research, vol. 95, no. 5, pp. e45-e55, 2004.

[94] Y. Chang, B. Ceacareanu, M. Dixit, N. Sreejayan, and A. Hassid, "Nitric oxide-induced motility in aortic smooth muscle cells: role of protein tyrosine phosphatase SHP-2 and GTPbinding protein Rho," Circulation Research, vol. 91, no. 5, pp. 390-397, 2002.

[95] Z. Chen, S. Ishibashi, S. Perrey, et al., "Troglitazone inhibits atherosclerosis in apolipoprotein E-knockout mice: pleiotropic effects on CD36 expression and HDL," Arteriosclerosis, Thrombosis, and Vascular Biology, vol. 21, no. 3, pp. 372-377, 2001.

[96] A. R. Collins, W. P. Meehan, U. Kintscher, et al., "Troglitazone inhibits formation of early atherosclerotic lesions in diabetic and nondiabetic low density lipoprotein receptordeficient mice," Arteriosclerosis, Thrombosis, and Vascular Biology, vol. 21, no. 3, pp. 365-371, 2001.

[97] A. C. Li, K. K. Brown, M. J. Silvestre, T. M. Willson, W. Palinski, and C. K. Glass, "Peroxisome proliferator-activated receptor $\gamma$ ligands inhibit development of atherosclerosis in LDL receptor-deficient mice," Journal of Clinical Investigation, vol. 106, no. 4, pp. 523-531, 2000.

[98] S. Goetze, A. Bungenstock, C. Czupalla, et al., "Leptin induces endothelial cell migration through Akt, which is inhibited by PPAR $\gamma$-ligands," Hypertension, vol. 40, no. 5, pp. 748-754, 2002.

[99] C. M. Halabi and C. D. Sigmund, "Peroxisome proliferatoractivated receptor- $\gamma$ and its agonists in hypertension and atherosclerosis: mechanisms and clinical implications," American Journal of Cardiovascular Drugs, vol. 5, no. 6, pp. 389-398, 2005.

[100] R. Avena, M. E. Mitchell, E. S. Nylen, K. M. Curry, and A. N. Sidawy, "Insulin action enhancement normalizes brachial artery vasoactivity in patients with peripheral vascular disease and occult diabetes," Journal of Vascular Surgery, vol. 28, no. 6, pp. 1024-1032, 1998, discussion 1031-1032.

[101] L. Cominacini, U. Garbin, A. Fratta Pasini, et al., "Troglitazone reduces LDL oxidation and lowers plasma E-selectin 
concentration in NIDDM patients," Diabetes, vol. 47, no. 1, pp. 130-133, 1998.

[102] T. Murakami, S. Mizuno, K. Ohsato, et al., "Effects of troglitazone on frequency of coronary vasospastic-lnduced angina pectoris in patients with diabetes mellitus," American Journal of Cardiology, vol. 84, no. 1, pp. 92-94, 1999.

[103] A. B. Walker, P. D. Chattington, R. E. Buckingham, and G. Williams, "The thiazolidinedione rosiglitazone (BRL-49653) lowers blood pressure and protects against impairment of endothelial function in Zucker fatty rats," Diabetes, vol. 48, no. 7, pp. 1448-1453, 1999.

[104] Q. N. Diep, M. El Mabrouk, J. S. Cohn, et al., "Structure, endothelial function, cell growth, and inflammation in blood vessels of angiotensin II-infused rats: role of peroxisome proliferator-activated receptor- $\gamma$," Circulation, vol. 105, no. 19, pp. 2296-2302, 2002.

[105] K. Takeda, T. Ichiki, T. Tokunou, et al., "Peroxisome proliferator-activated receptor $\gamma$ activators downregulate angiotensin II type 1 receptor in vascular smooth muscle cells," Circulation, vol. 102, no. 15, pp. 1834-1839, 2000.

[106] J. Minamikawa, S. Tanaka, M. Yamauchi, D. Inoue, and H. Koshiyama, "Potent inhibitory effect of troglitazone on carotid arterial wall thickness in type 2 diabetes," Journal of Clinical Endocrinology and Metabolism, vol. 83, no. 5, pp. 1818-1820, 1998.

[107] T. Takagi, T. Akasaka, A. Yamamuro, et al., "Troglitazone reduces neointimal tissue proliferation after coronary stent implantation in patients with non-insulin dependent diabetes mellitus: a serial intravascular ultrasound study," Journal of the American College of Cardiology, vol. 36, no. 5, pp. 1529$1535,2000$.

[108] J. S. Sidhu, Z. Kaposzta, H. S. Markus, and J. C. Kaski, "Effect of rosiglitazone on common carotid intima-media thickness progression in coronary artery disease patients without diabetes mellitus," Arteriosclerosis, Thrombosis, and Vascular Biology, vol. 24, no. 5, pp. 930-934, 2004.

[109] J. Hetzel, B. Balletshofer, K. Rittig, et al., "Rapid effects of rosiglitazone treatment on endothelial function and inflammatory biomarkers," Arteriosclerosis, Thrombosis, and Vascular Biology, vol. 25, no. 9, pp. 1804-1809, 2005.

[110] U. Campia, L. A. Matuskey, and J. A. Panza, "Peroxisome proliferator-activated receptor- $\gamma$ activation with pioglitazone improves endothelium-dependent dilation in nondiabetic patients with major cardiovascular risk factors," Circulation, vol. 113, no. 6, pp. 867-875, 2006.

[111] S. Ameshima, H. Golpon, C. D. Cool, et al., "Peroxisome proliferator-activated receptor gamma ( $\operatorname{PPAR} \gamma)$ expression is decreased in pulmonary hypertension and affects endothelial cell growth," Circulation Research, vol. 92, no. 10, pp. 1162 1169, 2003.

[112] D. Bishop-Bailey and T. Hla, "Endothelial cell apoptosis induced by the peroxisome proliferator- activated receptor (PPAR) ligand 15-deoxy- $\Delta^{12,14}$-prostaglandin $\mathrm{J}_{2}$," Journal of Biological Chemistry, vol. 274, no. 24, pp. 17042-17048, 1999.

[113] M. B. Dancu, D. E. Berardi, J. P. Vanden Heuvel, and J. M. Tarbell, "Asynchronous shear stress and circumferential strain reduces endothelial NO synthase and cyclooxygenase2 but induces endothelin-1 gene expression in endothelial cells," Arteriosclerosis, Thrombosis, and Vascular Biology, vol. 24, no. 11, pp. 2088-2094, 2004.

[114] J. Hwang, A. Saha, Y. C. Boo, et al., "Oscillatory shear stress stimulates endothelial production of $\mathrm{O}_{2}^{-}$from $\mathrm{p} 47^{\text {phox }}$-dependent $\mathrm{NAD}(\mathrm{P}) \mathrm{H}$ oxidases, leading to monocyte adhesion," Journal of Biological Chemistry, vol. 278, no. 47, pp. 47291-47298, 2003.

[115] J. S. McNally, M. E. Davis, D. P. Giddens, et al., "Role of xanthine oxidoreductase and $\mathrm{NAD}(\mathrm{P}) \mathrm{H}$ oxidase in endothelial superoxide production in response to oscillatory shear stress," American Journal of Physiology, vol. 285, no. 6, pp. H2290-H2297, 2003.

[116] Y. Matsuda, Y. Hoshikawa, S. Ameshima, et al., "Effects of peroxisome proliferator-activated receptor $\gamma$ ligands on monocrotaline-induced pulmonary hypertension in rats," Nihon Kokyuki Gakkai Zasshi, vol. 43, no. 5, pp. 283-288, 2005.

[117] Y. Lin, X. Zhu, F. L. McIntee, H. Xiao, J. Zhang, M. Fu, and Y. E. Chen, "Interferon regulatory factor-1 mediates $\operatorname{PPAR} \gamma$ induced apoptosis in vascular smooth muscle cells," Arteriosclerosis, Thrombosis, and Vascular Biology, vol. 24, no. 2, pp. 257-263, 2004.

[118] T. Okura, M. Nakamura, Y. Takata, S. Watanabe, Y. Kitami, and K. Hiwada, "Troglitazone induces apoptosis via the p53 and Gadd45 pathway in vascular smooth muscle cells," European Journal of Pharmacology, vol. 407, no. 3, pp. 227-235, 2000.

[119] K. R. Stenmark and I. F. McMurtry, "Vascular remodeling versus vasoconstriction in chronic hypoxic pulmonary hypertension: a time for reappraisal?" Circulation Research, vol. 97, no. 2, pp. 95-98, 2005.

[120] J. T. Crossno Jr., K. G. Morris Jr., and D. J. Klemm, "Attenuation of hypoxia-induced pulmonary artery remodeling by a peroxisome proliferator-activated receptor- $\gamma$ agonist," Chest, vol. 128, supplement 6, p. 580S, 2005.

[121] J. Hwang, D. J. Kleinhenz, H. L. Rupnow, et al., “The PPAR $\gamma$ ligand, rosiglitazone, reduces vascular oxidative stress and NADPH oxidase expression in diabetic mice," Vascular Pharmacology, vol. 46, no. 6, pp. 456-462, 2007. 


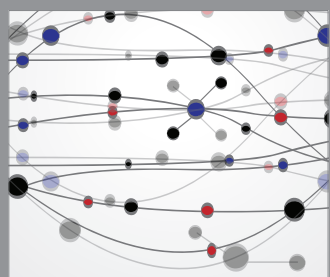

The Scientific World Journal
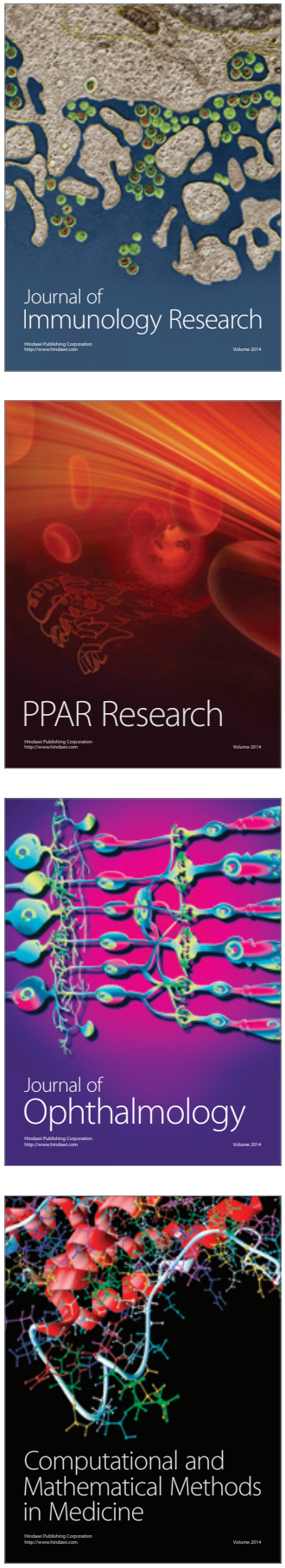

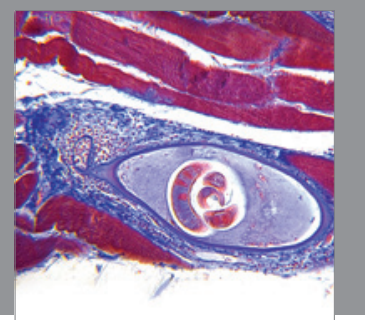

Gastroenterology

Research and Practice
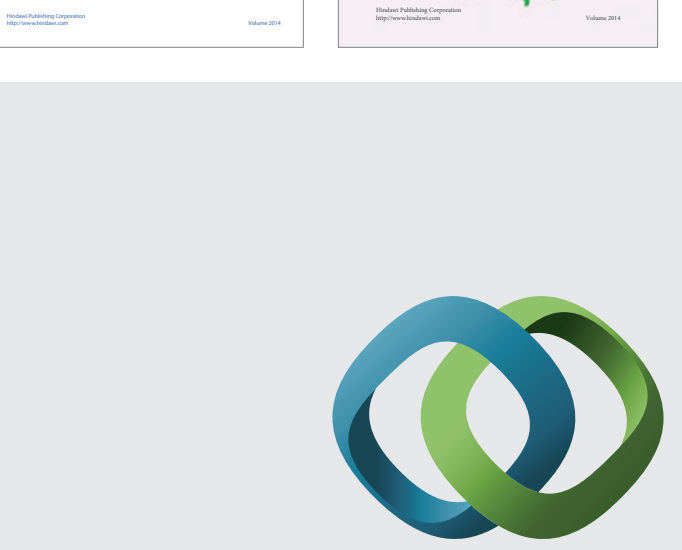

\section{Hindawi}

Submit your manuscripts at

http://www.hindawi.com
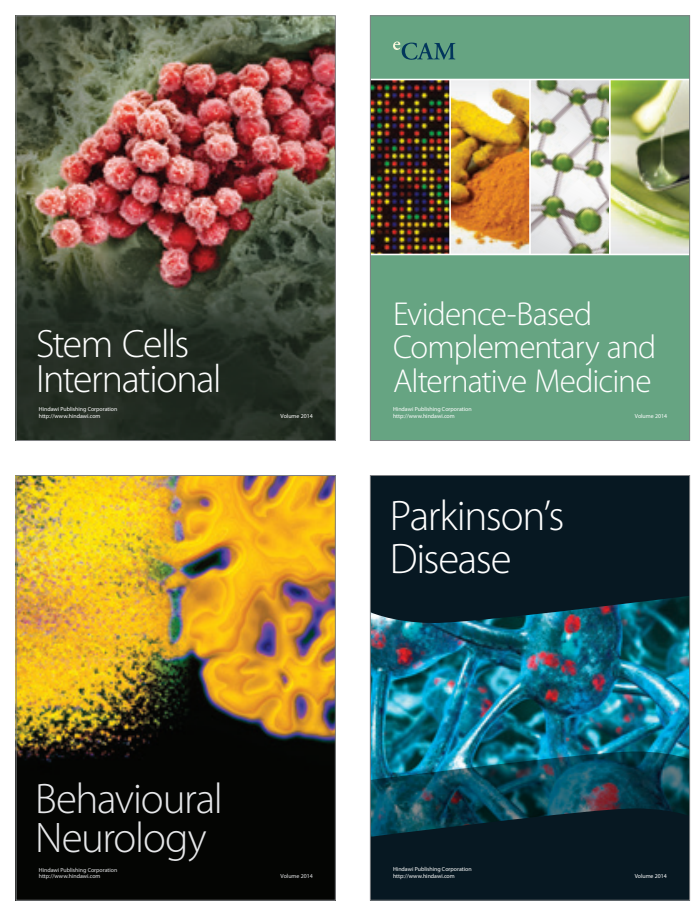

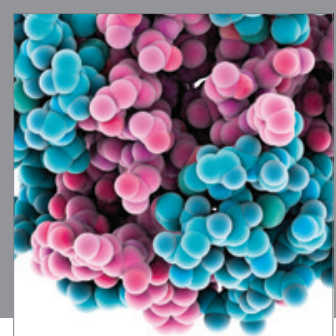

Journal of
Diabetes Research

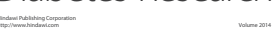

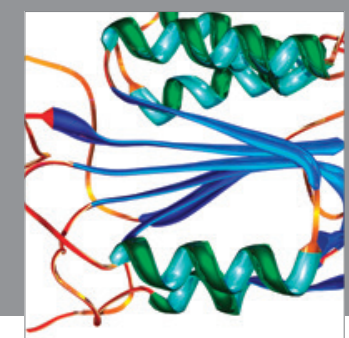

Disease Markers
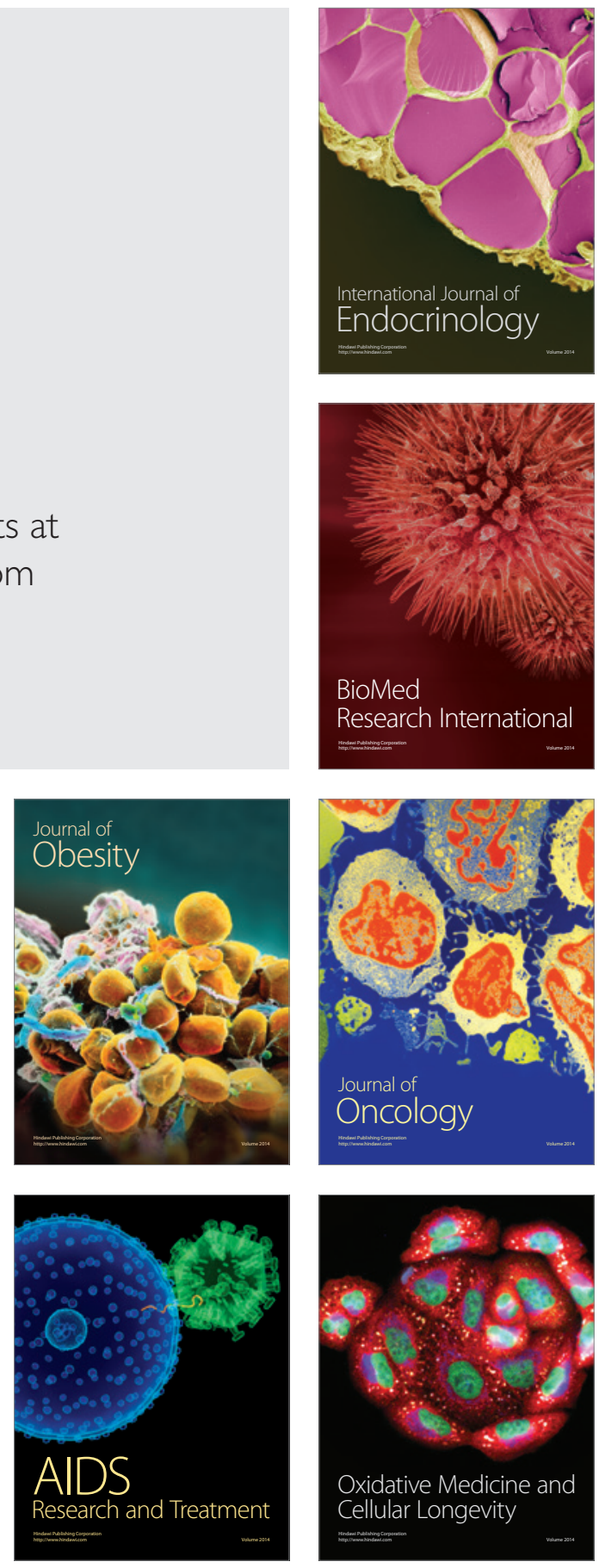